Proc. of the XI Int. Conf. - Ion Implantation and other Applications of Ions and Electrons, Kazimierz Dolny 2016

\title{
Application of Ion Implantation for Intermediate Energy Levels Formation in the Silicon-Based Structures Dedicated for Photovoltaic Purposes
}

\author{
P. Billewicz ${ }^{a}$, P. WęgiereK ${ }^{a, *}$, T. Grudniewski ${ }^{b}$ And M. TureK ${ }^{c}$ \\ ${ }^{a}$ Lublin University of Technology, Nadbystrzycka 38A, 20-618 Lublin, Poland \\ ${ }^{b}$ Pope John Paul II State School of Higher Vocational Education, Sidorska 95/97, 21-500 Biała Podlaska, Poland \\ ${ }^{c}$ Institute of Physics, Maria Curie-Skłodowska University, Pl. M. Curie-Skłodowskiej 1, 20-031 Lublin, Poland
}

\begin{abstract}
The main aim of the research was to verify if it is possible to create the intermediate energy levels in silicon by means of ion implantation as well as to confirm whether the intermediate band could arise. The tests covered recording of conductance and capacitance of antimony-doped silicon, implanted with $\mathrm{Ne}^{+}$ions. As a result, it was possible to identify a single deep level in the sample and determine its location in the band gap by estimating the value of activation energy.
\end{abstract}

DOI: 10.12693 /APhysPolA.132.274

PACS/topics: 61.72.uf, 71.55.Eq, 88.40.hj

\section{Introduction}

The technological progress made in the field of crystalline silicon photovoltaic (PV) cells over the last few years resulted in a number of innovative concepts, which were analyzed in a number of scientific reports [1-3]. The vast majority of described solutions were focused on increasing the actual solar cells efficiency by means of reducing optical, electrical and quantum loss factors in order to minimize their detrimental effects on the photoconversion process. However, achieving this objective imposes the formation of silicon structures which are significantly more complex than a conventional PV cell and, consequently, introduce much more precise material-processing technology. For that reason, the potential of ion implantation as the alternative technique of obtaining silicon substrates applicable in photovoltaics was the subject of many research works [4-6]. Summarizing the results of those analyses the authors pointed out the flexibility and many other advantages of such methodology, including the ability to produce uniform junctions, selective emitters and interdigitated back contact (IBC) cells, as well as the opportunity to eliminate edge isolation and dopant gas removal processes. However, the importance of proper understanding of interactions between particular parameters of ion implantation and appropriate selection of such conditions as energy, fluence, annealing strategy, doping profiles and bulk lifetime, in order to obtain expected outcomes, was highlighted as well. In our previous paper [7] we also contributed to ongoing discussion, proposing the application of ion implantation to enhance thermal stability of electrical parameters of silicon used in the PV cells production process.

*corresponding author; e-mail: p.wegierek@pollub.pl
Contrary to the approach described above, which was aimed at reducing the negative impact of certain parasitic phenomena, another idea of improving performance of PV cells is currently under consideration. As it is commonly known, efficiency of a solar cell is strongly dependent on the value of band-gap energy $\left(E_{g}\right)$ which is characteristic of certain substrate material [8]. Furthermore, the results of numerical simulation presented in [9] are strictly correlated with this general dependence. In particular, the conducted calculations showed that a slight decrease in the value of $E_{g}$ significantly affects the value of $I-V$ characteristics fill factor $(\mathrm{FF})$. As it was reported, $\mathrm{FF}$ increases from $55 \%$ to over $78 \%$ as the $E_{g}$ is reduced by $0.07 \mathrm{eV}$. On the other hand, it was confirmed that applying ion implantation technology enables introduction of additional energy levels within the semiconductor band gap and allows controlling the depth of their location in the energy-band diagram [10]. In this context, it is reasonable to investigate if it is possible to induce a shift in the value of $E_{g}$ using appropriately configured ion implantation and whether such operation will influence the performance of PV cells. Since the ion implantation and post-implantation treatment are the processes that require predetermining of a number of correlated variables, the aspect of consideration was a matter of many experimental and theoretical studies [11-15].

According to the idea presented in [11] it is possible to utilize the ion implantation in order to create in the silicon lattice a number of deep energy levels by introducing impurities of the concentration higher than the Mott transition limit. This will result in appearance of a continuous intermediate band (IB) within the forbidden band of semiconductor, narrowing the band gap and reducing the Shockley-Read-Hall recombination simultaneously. As it was assumed, occurrence of this new band could allow the photons of energy lower than $E_{g}$ to be absorbed, generating additional photocurrent and 
consequently, increasing the PV cells efficiency. The possibility of IB formation was confirmed experimentally for different impurities such as titanium [12], sulphur [13], selenium and tellurium [14]. Moreover, this may be be possible for other elements such as chalcogens or transition metals. As a result, on the basis of experimental research conducted for titanium-implanted silicon, a detailed model of intermediate energy levels configuration was proposed [15]. The developed model theoretically explains the phenomena of energy level splitting, band gap narrowing and suppressing carrier recombination as a physical consequence of high impurities concentration. This also suggests methodology of analysis applicable to the materials of impurities concentration higher than the Mott limit.

Taking the above into consideration, it is justified to conduct further research, directed into verification of the phenomena revealed for other silicon impurities. The purpose of this paper is to investigate the effect of ion implantation on the energy levels distribution in silicon implanted with $\mathrm{Ne}^{+}$ions.

\section{Experimental}

The main aim of the research was to verify if it is possible to create the intermediate energy levels in silicon by means of ion implantation as well as to confirm whether the IB could arise. In contrast to our previous papers [1618], in which silicon doped with boron and phosphorus was considered, as the object of current study antimony was chosen as a dopant. Such initial condition is due to the fact that antimony has the relative atomic mass and electron configuration different from the dopant elements used previously, which will allow investigating possible correlations in further comparative analyses. Initial resistivity of the tested samples was equal to $\rho=0.01 \Omega \mathrm{cm}$. Implantation was accomplished at room temperature, using $\mathrm{Ne}^{+}$ions of the energy $E=100 \mathrm{keV}$ and the fluence $D$ ranging from $1.5 \times 10^{13} \mathrm{~cm}^{-2}$ to $2 \times 10^{15} \mathrm{~cm}^{-2}$. The tests covered recording the conductance and capacitance at ambient temperature $T_{p}=(77 \div 373) \mathrm{K}$. Frequency $f$ of the measurement signal ranged from $50 \mathrm{~Hz}$ to $5 \mathrm{MHz}$ and the bias voltage was equal to $0.4 \mathrm{~V}$. The samples were subjected to $15 \mathrm{~min}$ isochronous annealing, within the $T_{a}$ temperature up to $873 \mathrm{~K}$, with an average increase rate of $30 \div 50 \mathrm{~K}$. Detailed methodology, including preparation of the samples as well as the experimental setup was described in [10].

\section{Analysis of the obtained results}

In order to identify symptoms of the occurrence of deep levels which probably were formed in the tested material due to the $\mathrm{Ne}^{+}$implantation, the temperature dependences of the conductance (Fig. 1) and capacitance (Fig. 2) were plotted for the testing frequency value of $1 \mathrm{kHz}$ and for different annealing conditions. As it is commonly known the peaks and inflection points in the progression of respective conductance and capacitance plots versus temperature, indicate existence of a deep level in the semiconductor band gap. Considering the curves presented in Figs. 1 and 2, it is possible to distinguish such regions for the temperature $T_{a}=673 \mathrm{~K}$. The samples annealed at $473 \mathrm{~K}$ and $573 \mathrm{~K}$ reveal similar trends, however, they are not as evident, whereas the plot for $T_{a}=773 \mathrm{~K}$ remains almost unchanged across the whole range of $T_{p}$.

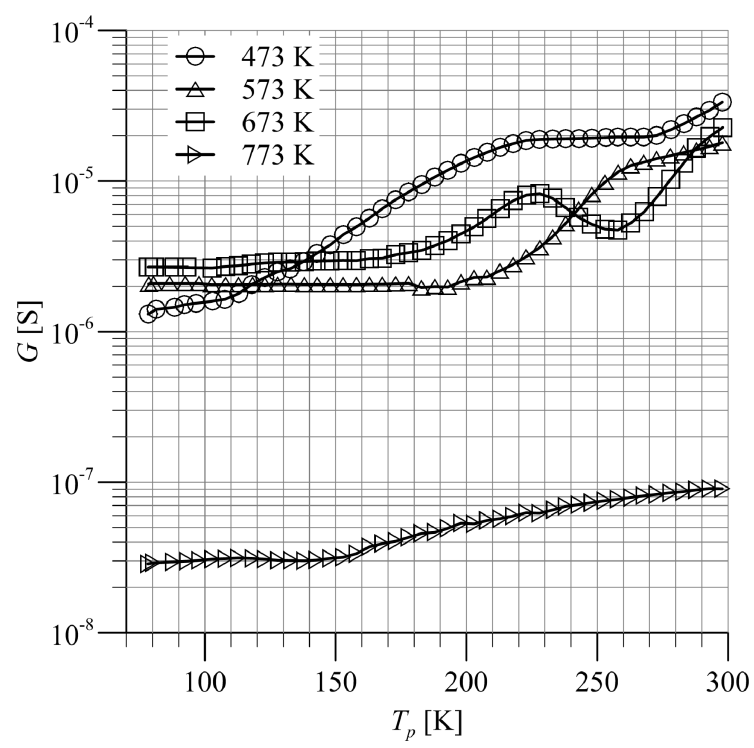

Fig. 1. Dependences $G=f\left(T_{p}\right)$ for $f=1 \mathrm{kHz}$ and different annealing temperatures $T_{a}$.

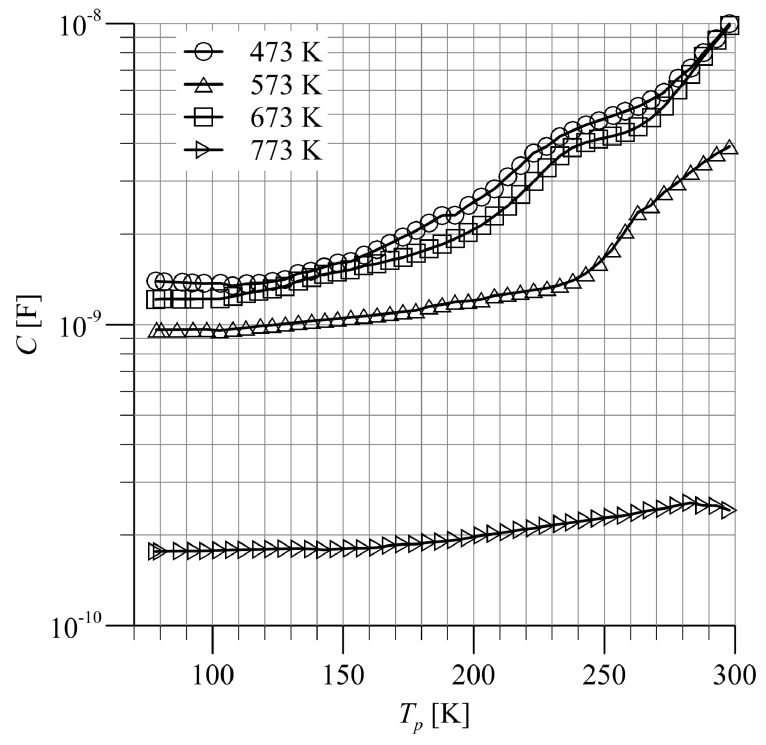

Fig. 2. Dependences $C=f\left(T_{p}\right)$ for $f=1 \mathrm{kHz}$ and different annealing temperatures $T_{a}$.

According to [19], the observed conductance maximum $G_{m}$ at a certain temperature $T_{m}$ is related to the deep level thermal emission rate $e^{t}\left(T_{m}\right)$ and satisfies the equa- 


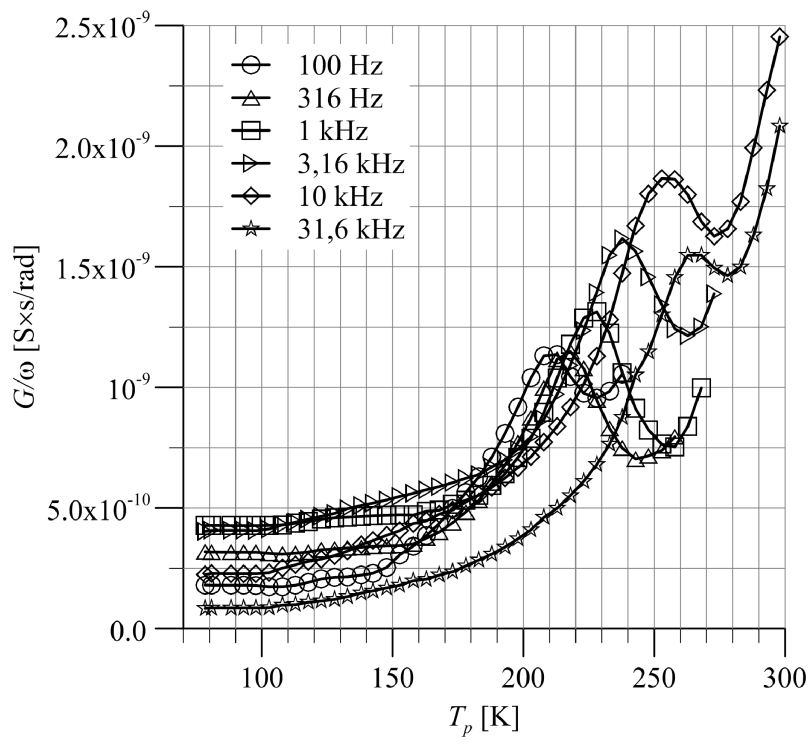

Fig. 3. Dependences $G / \omega=f\left(T_{p}\right)$ for $T_{a}=673 \mathrm{~K}$ and different values of testing frequency $f$.

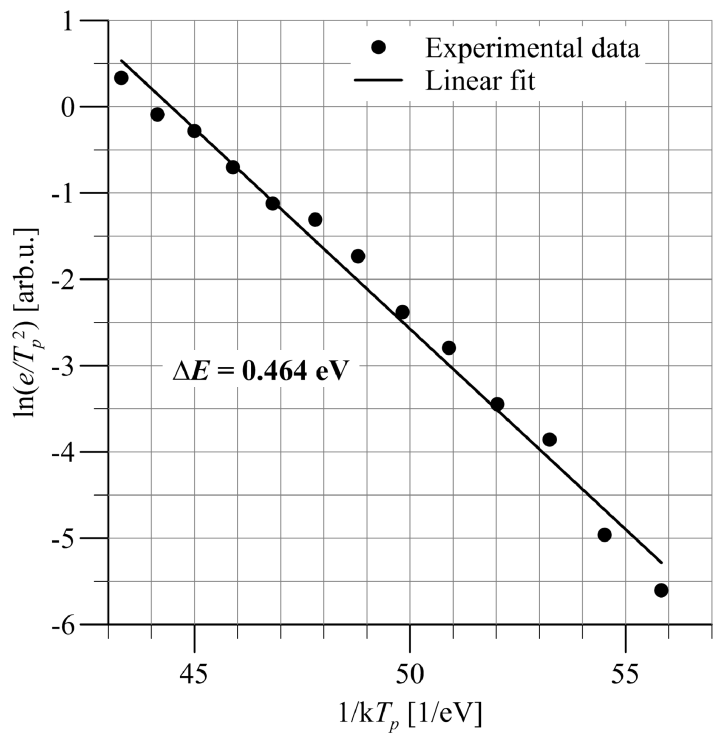

Fig. 4. Arrhenius plot of the function $\ln \left(e^{t}(T) / T^{2}\right)=$ $f(1 / k T)$ for $T_{a}=673 \mathrm{~K}$ and different values of testing frequency $f$.

tion

$$
e^{t}\left(T_{m}\right)=\omega / 1.98,
$$

where $\omega$ is the angular frequency. Consequently, in Fig. 3 the conductance signal versus the temperature was plotted for several testing frequencies and the value of $T_{a}=673 \mathrm{~K}$. As it can be seen, position of the peak-point of each recorded signal is distinctive for a certain value of $f$ and it shifts with the increasing temperature. This allows estimating the value of $\omega$ and subsequently the value of $e^{t}\left(T_{m}\right)$ according to formula (1).

On the other hand, it is known [20] that the thermal emission rate of a deep level could be expressed by

$$
e^{t}(T)=\sigma_{T} \nu_{t h} N_{C} \exp \left(-E_{T} / k T\right),
$$

where $\sigma_{T}$ - capture cross-section, $\nu_{t h}$ - carrier thermal velocity, $N_{C}-$ conduction band state density, $E_{T}-$ activation energy. Since it is known that $\nu_{t h}$ is proportional to $T^{1 / 2}$ and $N_{C}$ is proportional to $T^{3 / 2}$, Eq. (2) can be transformed into the following expression:

$$
e^{t}(T) / T^{2}=\gamma \sigma_{T} \exp \left(-E_{T} / k T\right),
$$

where $\gamma$ includes the $\nu_{t h}$ and $N_{C}$ factors and is not affected by temperature. Formula (3) obeys the Arrhenius plot law. For that reason, it was possible to obtain the deep level activation energy by approximating the experimental data, as shown in Fig. 4. The results of conducted analysis shows that detected deep level is characterized by the activation energy of $E_{T}=0.464 \mathrm{eV}$.

\section{Conclusions}

It was possible to identify a single deep level in the sample of antimony-doped silicon implanted with $\mathrm{Ne}^{+}$ ions. Subsequently, its location in the band gap was determined by estimating the value of $E_{T}$. Furthermore, there are some presumptions that occurrence of the IB band is probable. As it was pointed out, some of the recorded plots did not reveal symptoms of the existence of any deep levels. According to what was suggested in [12], such tendency coincides with the IB theory which assumes that recombination is suppressed when the IB band is formed. However, in order to confirm whether the intermediate band was actually formed, it is necessary to perform further analyses. In particular, it is necessary to implement a new analytical model, which takes into consideration the phenomena associated with the thermally activated mechanisms of carrier transport as it was described in [21]. Moreover, the influence of certain parameters of ion implantation, post-implantation treatment and testing conditions should also be considered.

\section{References}

[1] Y. Lee, C. Park, N. Balaji, Y.-J. Lee, V. A. Dao, Isr. J. Chem. 55, 1050 (2015).

[2] A. Chandra, G. Anderson, S. Melkote, W. Gao, H. Haitjema, K. Wegener, CIRP Ann. Manufact. Technol. 63, 797 (2014).

[3] V. Benda, J. Eng. Sci. Technol. Rev. 7, 7 (2014).

[4] C.-M. Lee, S.-P. Chang, S.-J. Chang, C.-I. Wu,. Int. J. Electrochem. Sci. 8, 7634 (2013).

[5] C.-M. Lee, S.-P. Chang, S.-J. Chang, C.-I. Wu, Int. J. Photoenergy 2012, 670981 (2012).

[6] A. Rohatgi, D.L. Meier, B. McPherson, Y.-W. Ok, A.D. Upadhyaya, J.-H. Lai, F. Zimbardi, Energy Proced. 15, 10 (2012).

[7] P. Węgierek, P. Billewicz, Acta Phys. Pol. A 128, 943 (2015).

[8] A. Luque, S. Hegedus, Handbook of Photovoltaic Science and Engineering, 2nd ed., Wiley, Chichester 2011. 
[9] U.K. Das, S. Bowden, M. Lu, M.Z. Burrows, O. Jani, D. Xu, S.S. Hegedus, R.L. Opila, R.W. Birkmire, Progress towards High Efficiency All-Back-Contact Heterojunction c-Si Solar Cells, Institute of Energy Conversion, University of Delaware, Newark 2010.

[10] P. Węgierek, Electric Conduction in Strongly Defected Semiconductors Modified by Ion Implantation Technology, Lublin University of Technology, Lublin 2013.

[11] J. Olea, D. Pastor, A. del Prado, E. Garcia-Hemme, R. Garcia-Hernansanz, I. Martil, G. Gonzalez-Diaz, J. Appl. Phys. 114, 053110 (2013).

[12] H. Castan, E. Perez, H. Garcia, S. Duenas, L. Bailon, J. Olea, D. Pastor, E. Garcia-Hemme, M. Irigoyen, G. Gonzalez-Diaz, J. Appl. Phys. 113, 024104 (2013).

[13] J.T. Sullivan, C.B. Simmons, J.J. Krich, A.J. Akey, D. Recht, M.J. Aziz, T. Buonassisi, J. Appl. Phys. 114, 103701 (2013).

[14] I. Umezu, J.M. Warrender, S. Charnvanichborikarn, A. Kohno, J.S. Williams, M. Tabbal, D.G. Papazoglou, X.-C. Zhang, M.J. Aziz, J. Appl. Phys. 113 231501 (2013).
[15] E. Perez, S. Duenas, H. Castan, H. Garcia, L. Bailon, D. Montero, R. Garcia-Hernansanz, E. GarciaHemme, J. Olea, G. Gonzalez-Diaz, J. Appl. Phys. 118, 245704 (2015).

[16] P. Węgierek, P. Billewicz, Acta Phys. Pol. A 123, 948 (2013).

[17] P. Węgierek, P. Billewicz, Acta Phys. Pol. A $\mathbf{1 2 0}$ 122 (2011).

[18] O. Zinchuk, N. Drozdov, A. Fedotov, A. Mazanik, N. Krekotsen, V. Ukhov, J. Partyka, P. Węgierek, T. Kołtunowicz, Vacuum 83, S99 (2009).

[19] J. Barbolla, S. Duenas, L. Bailon, Solid-State Electron. 35, 285 (1992).

[20] D.K. Schroder, Semiconductor Material and Device Characterization, 3rd ed., Wiley, New Jersey 2006.

[21] J. Partyka, P.W. Żukowski, P. Węgierek, A. Rodzik, Yu.V. Sidorenko, Yu.A. Shostak, Semiconductors 36, 1326 (2002). 